\title{
Increase in types IV and VI collagen in cherry haemangiomas*
}

\author{
E. Tamm ${ }^{1}$, W. Jungkunz ${ }^{2}$, W. Ch. Marsch ${ }^{2}$, and E. Lütjen-Drecoll ${ }^{1}$ \\ 1 Department of Anatomy, Friedrich-Alexander University of Erlangen-Nürnberg, Lehrstuhl II, Universitätsstrasse 19, W-8520 Erlangen, \\ Federal Republic of Germany \\ 2 Department of Dermatology, Johann Wolfgang Goethe University of Frankfurt/Main, W-6000 Frankfurt/Main, Federal Republic of \\ Germany
}

Received December 4, 1991

Summary. The capillaries in cherry haemangiomas show perivascular hyalinized sheaths. In order to clarify the nature of this sheath material, the extracellular matrix of cherry haemangiomas from 20 normal volunteers (age range 30-64 years) was investigated using immunohistochemical and electronmicroscopical methods. Antibodies against collagen types III, IV and VI and laminin were used. Hyaluronic acid was visualized using the hyaluronic acid binding region of the cartilage proteoglycan as ligand. Electronmicroscopically, the sheaths contained multilaminated basement membrane-like material, collagen fibres 20-25 nm thick with a periodicity of $67 \mathrm{~nm}$ and broadbanded aggregates with a periodicity of $100 \mathrm{~nm}$ (zebra bodies or fibrous long-spacing fibres). Immunohistochemically, type IV collagen was stained throughout the whole sheath material. Staining for laminin was more confined to the endothelial side of the sheath. Intense staining for type III collagen and hyaluronic acid was found in the connective tissue of the subpapillary layer and between the cherry haemangioma capillaries. Much weaker staining for type III collagen and no staining for hyaluronic acid were found invariably in an area 4-10 $\mu \mathrm{m}$ thick directly around the capillaries. Both sheath material and intercapillary connective tissue of the haemangiomas showed pronounced staining for collagen type VI. Immunogold staining revealed that type VI collagen was localized to microfibrils 5-6 nm thick and to the broad-banded aggregates with $100 \mathrm{~nm}$ periodicity. These findings further underline the assumption that the broad-banded aggregates consist of type VI collagen.

Key words: Cherry haemangioma - Type IV collagen - Type VI collagen - Immunohistochemistry - U1trastructure

\footnotetext{
* This paper was presented in part at the XVIIIth Annual Meeting of the Arbeitsgemeinschaft Dermatologische Forschung (ADF), 9-11 November 1990, Mannheim, FRG

Cherry haemangiomas (senile angiomas [41] or Campell de Morgan's spots [33]) are benign tumours of subpapillary capillaries. They mainly derive from the venous limb of the capillary loops and are arranged lobular-like $[41,2,23]$. The capillaries in mature cherry haemangiomas are often surrounded by a perivascular sheath of extracellular material. This sheath is as thick as $10 \mu \mathrm{m}$ and stains eosinophilic and PAS positive [41]. It has been suggested that the sheath material comprises 'degenerated' or 'homogenized" collagen [23, 41], but its nature and origin are still unclear. Electronmicroscopically, multilaminated basement membrane-like material $[2,43]$, thin collagen or 'reticulin' fibres $[2,43]$ and zebra bodies or fibrous long-spacing fibres [2] have been observed around cherry haemangioma capillaries.

To further clarify the nature of the sheath material, we analysed the distribution of different extracellular matrix components in cherry haemangiomas with immunohistochemical methods. To identify basement membrane components in the sheath material we used antibodies against the typical basement membrane proteins, type IV collagen and laminin [11, 31]. We also stained type III collagen, which is regarded as the major component of reticulin fibres in the adventitial dermis [29]. In previous ultraimmunohistochemical studies we were able to demonstrate that in the human eye, broad-banded aggregates similar to zebra bodies or fibrous long-spacing fibres stain with polyclonal antibodies against type VI collagen $[25,37]$. We therefore studied the localization of type VI collagen in the sheath material of cherry haemangioma capillaries both light- and electron-microscopically.

\section{Materials and methods}

\section{Cherry haemangiomas}

Cherry haemangiomas from 20 normal healthy volunteers $(30-64$ years of age, mean 47.8 years) were investigated. The haemangiomas measured $0.5-3 \mathrm{~mm}$ in diameter and were removed from the skin of the trunk. One haemangioma was obtained from the upper arm. Three of the volunteers contributed multiple haemangiomas. An intradermal ring of anaesthesia was produced around the haem- 
angioma with $1 \%$ lignocaine without epinephrine. Discs of skin as thick as 3-4 $\mathrm{mm}$ containing the haemangioma were excised with a skin trephine from the centre of the ring and processed both for light and electron-microscopy.

\section{Light microscopy}

For paraffin sections, five samples were fixed in $10 \%$ phosphatebuffered formalin for 2 days and six samples in phosphate-buffered periodate-lysine paraformaldehyde (PLP) solution [32] for $4 \mathrm{~h}$ at $4{ }^{\circ} \mathrm{C}$. The samples came from different donors. For demonstration of hyaluronic acid, three samples from different donors were fixed in $4 \%$ buffered formaldehyde containing $1 \%$ cetyl pyridium chloride for $4 \mathrm{~h}$. After washing in phosphate-buffered saline (PBS), the material was embedded in paraffin. Sections were cut $5 \mu \mathrm{m}$ thick and were either stained by Crossmon's trichrome stain [6] or further processed for immunohistochemistry.

For frozen sections, three samples were quick-frozen in isopentane, precooled with liquid nitrogen. Sections $10 \mu \mathrm{m}$ thick were fixed in acetone for $10 \mathrm{~min}$ at $-20^{\circ} \mathrm{C}$.

\section{Electron-microscopy}

Eight haemangiomas were fixed in $2.5 \%$ phosphate-buffered glutaraldehyde for at least $24 \mathrm{~h}$ at $4{ }^{\circ} \mathrm{C}$. After postfixation with $2 \%$ osmium tetroxide, the samples were embedded in Araldit (Roth, Karlsruhe, FRG). Semithin sections were stained with toluidine blue. Ultrathin sections were contrasted with lead citrate and uranyl acetate and viewed with a Zeiss EM 902 electron microscope.

\section{Immunohistochemistry}

After fixation, the frozen sections were preincubated for 45 min in Blotto's dry milk solution [7]. The paraffin sections were deparaffinized and preincubated first with $0.1 \%$ bovine testicular hyaluronidase (Serva, Heidelberg, FRG) for $20 \mathrm{~min}$, followed by $0.1 \%$ pronase E from Streptomyces griseus for $20 \mathrm{~min}$ and Blotto's solution for $30 \mathrm{~min}$.

Laminin and types IV and VI collagen. After preincubation, the sections were treated with the primary antibody for $90 \mathrm{~min}$. For demonstration of type IV collagen, monoclonal mouse antibodies from Heyl, Berlin, FRG (anti-human IgM, Kappa) and from Dakopatts, Hamburg, FRG (anti-human, IgG1 Kappi. CIV22 [34]) were used at a dilution of $1: 100$. For laminin, polyclonal rabbit anti-human antibodies from Heyl [1] were applied to the slides at a dilution of $1: 10$. Type VI collagen was demonstrated using a monoclonal mouse antibody (anti-human, Ig1, Kappa) and polyclonal rabbit anti-human antibodies (both from Heyl [42]) at a dilution of $1: 50$. After washing in PBS, the sections were incubated with fluorescein-labelled rabbit anti-mouse IgG (Dakopatts) or sheep anti-rabbit IgG diluted in PBS $(1: 20)$. The sections were mounted in Entellan (Merck, Darmstadt, FRG) containing 2.5\% 1,4-diazobicyclo-octane (Merck [19]) and viewed with a Leitz. Aristoplan microscope (Ernst Leitz GmbH, Wetzlar, FRG). A Kodak T-max 400 film was used for photography.

Type III collagen. The slides were incubated in $1 \% \mathrm{H}_{2} \mathrm{O}_{2}$ for $10 \mathrm{~min}$ and in 10\% bovine serum albumin (Sigma) for $20 \mathrm{~min}$. Mouse monoclonal antibodies against human type III collagen from Heyl (IgG2a, Kappa) were applied to the slides at a dilution of 1:50 for $60 \mathrm{~min}$, followed by biotinylated antibodies against mouse $\mathrm{Ig}$ (Amersham, Braunschweig, FRG), raised in sheep, diluted 1:200 for $30 \mathrm{~min}$. Then the sections were incubated with a streptABComplex (Amersham) for 45 min. Finally, diaminobenzidine (Sigma) staining for peroxidase activity was performed as described by Graham and Karnovsky [13].
Hyaluronic acid. Staining for hyaluronic acid was performed as described previously [26]. In brief, the hyaluronic acid-binding region of the cartilage proteoglycan was isolated, linked with biotin and used in histological sections as a ligand for hyaluronic acid. Staining was performed using the avidin-biotin-perioxidase technique.

\section{Immunoelectron-microscopy}

Samples (three from different donors) were fixed in PLP for $4 \mathrm{~h}$. After fixation, the samples were infiltrated with London Resin (LR) white (London Resin Co., Basingstoke, UK). Ultrathin sections were mounted on nickel grids. A drop of Blotto's dry milk solution was applied to the grids for $20 \mathrm{~min}$ at room temperature. After washing in PBS, the grids were incubated overnight at $4{ }^{\circ} \mathrm{C}$ with the polyclonal antibodies against type VI collagen (1:50). After ten 3-min changes in PBS, the grids were preincubated in normal goat serum (Sigma) for $30 \mathrm{~min}$ at room temperature. After washing three times in PBS, the grids were incubated for $30 \mathrm{~min}$ in a $1: 20$ dilution of goat anti-rabbit immunogold (10 nm, Sigma). Unbound gold was removed by ten 3 -min changes in PBS. The grids were fixed with $2 \%$ glutaraldehyde for $5 \mathrm{~min}$, washed and contrasted with uranyl acetate and lead citrate before examination with the electron microscope.

Controls. Control experiments were performed using either PBS or a mouse or rabbit pre-immune serum (Sigma) instead of the primary antibody. Control sections for hyaluronic acid staining were incubated for $120 \mathrm{~min}$ at $37^{\circ} \mathrm{C}$ with $50 \mathrm{U} / \mathrm{ml}$ of Streptomyces hyaluronidase in the presence of various protease inhibitors (Seikagaku Fine Biochemicals, Tokyo, Japan ) [26].

All antibodies had been tested using ELISA, immunoblot and immunohistology/assays.

\section{Results}

\section{Light microscopy}

The cherry haemangiomas investigated in this study showed the typical histological characteristics described

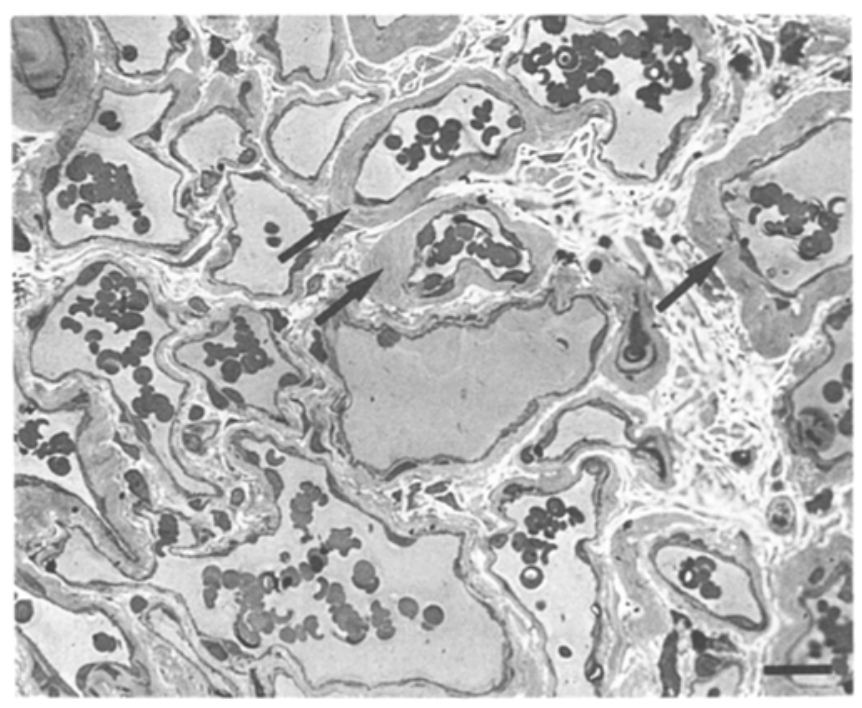

Fig. 1. Semithin section of a cherry haemangioma from a 32-yearold donor (toluidine blue; $\times 300 ;$ bar $23 \mu \mathrm{m}$ ). The capillaries show dilated lumina lined with flattened endothelial cells and are surrounded by a homogeneous sheath of extracellular material (arrows), which is often as thick as $10 \mu \mathrm{m}$ 
previously $[2,23,41,43]$. In small lesions, most of the capillaries were narrow and lined by prominent endothelial cells. Some of the capillaries, however, showed diluted lumina lined with flattened endothelial cells. These capillaries were surrounded by a homogeneous sheath of extracellular material which was often as thick as $10 \mu \mathrm{m}$ (Fig. 1). Such capillaries predominated in the mature, larger cherry haemangiomas. The morphology of the extracellular material between the capillaries and their sheaths did not obviously differ from that of the subpapillary region of normal skin from corresponding regions.

\section{Electron microscopy}

The endothelial cells of cherry haemangioma capillaries were surrounded by an incomplete layer of pericytes and a continuous basal lamina. A characteristic feature in most of the capillaries was the additional formation of multiple layers of basal lamina-like material which surrounded the capillaries concentrically. The number of these layers differed between individual capillaries. In the narrow capillaries with prominent endothelial cells, there were only $2-3$ additional layers present. Between the layers, electron-lucent ground substance with interspersed microfibrils 5-10 nm thick and collagen fibrils $20-25 \mathrm{~nm}$ thick with the typical periodicity of $67 \mathrm{~nm}$ were usually observed. In contrast to this, the number of additional layers increased considerably in the dilated capillaries with flattened endothelial cells, and thus covered a perivascular area as thick as $5 \mu \mathrm{m}$ (Fig. $2 \mathrm{~A}, \mathrm{~B}$ ). Around those capillaries in which light microscopy had shown the presence of the homogeneous sheath material, numerous layers of the basal lamina-like material were invariably observed. Here, the layers were embedded in moderate electron-dense flocculent or granular material (Fig. 2). In addition, there were numerous microfibrils 5-10 $\mathrm{nm}$ thick present. The microfibrils were aligned with numerous broad-banded aggregates resembling zebra collagen or long-spacing collagen (Fig. 2). The aggregates consisted of alternating light- and dark bands spaced with a periodicity of $100 \mathrm{~nm}$ (Fig. 2C). In general, these

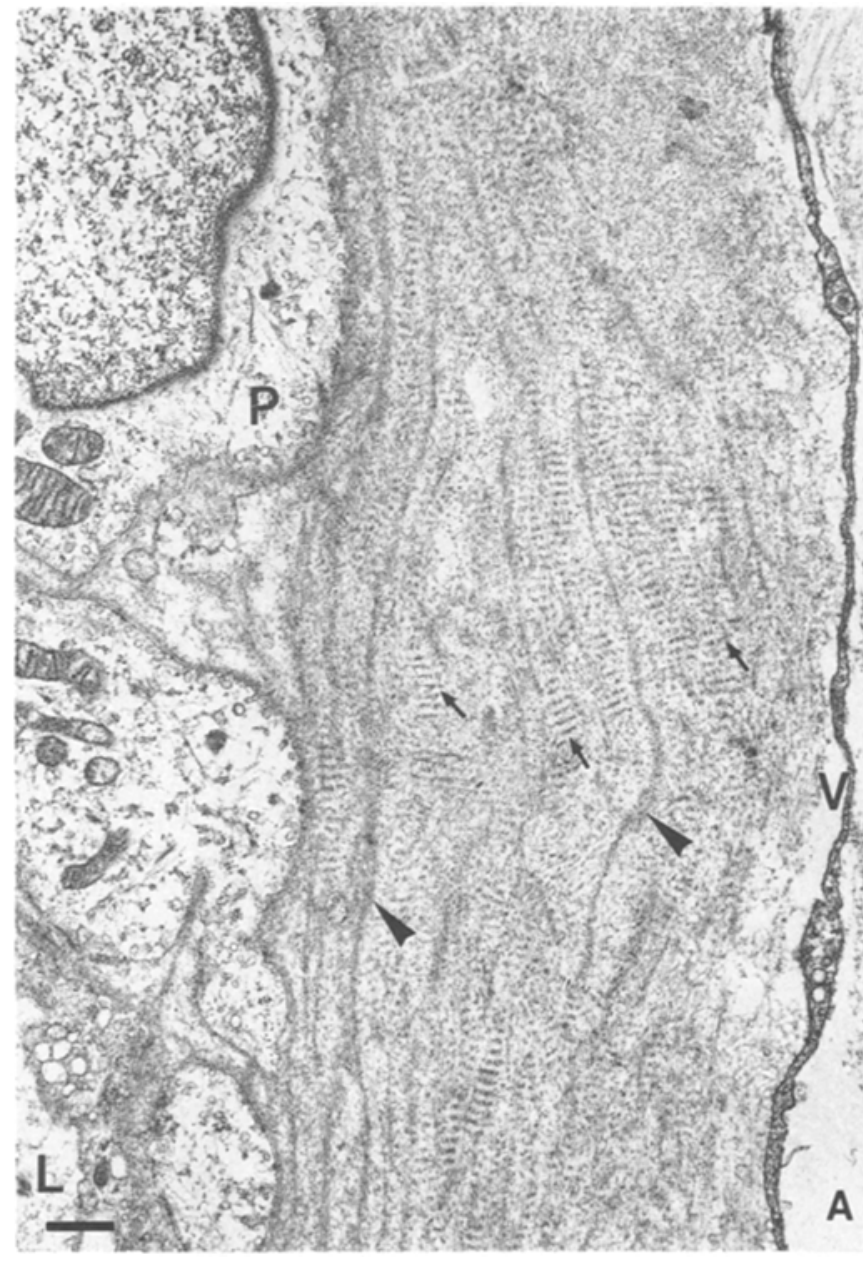

Fig. 2 A-C. Electronmicrographs of the cherry haemangioma sheath material, same case as in Fig. 1. A, B Multiple layers of basal lamina-like material (arrowheads) are embedded in moderate electron-dense granular material. In addition, numerous broadbanded aggregates with a periodicity of $100 \mathrm{~nm}$ are seen (arrows). The sheath material is separated from the intercapillary stroma by

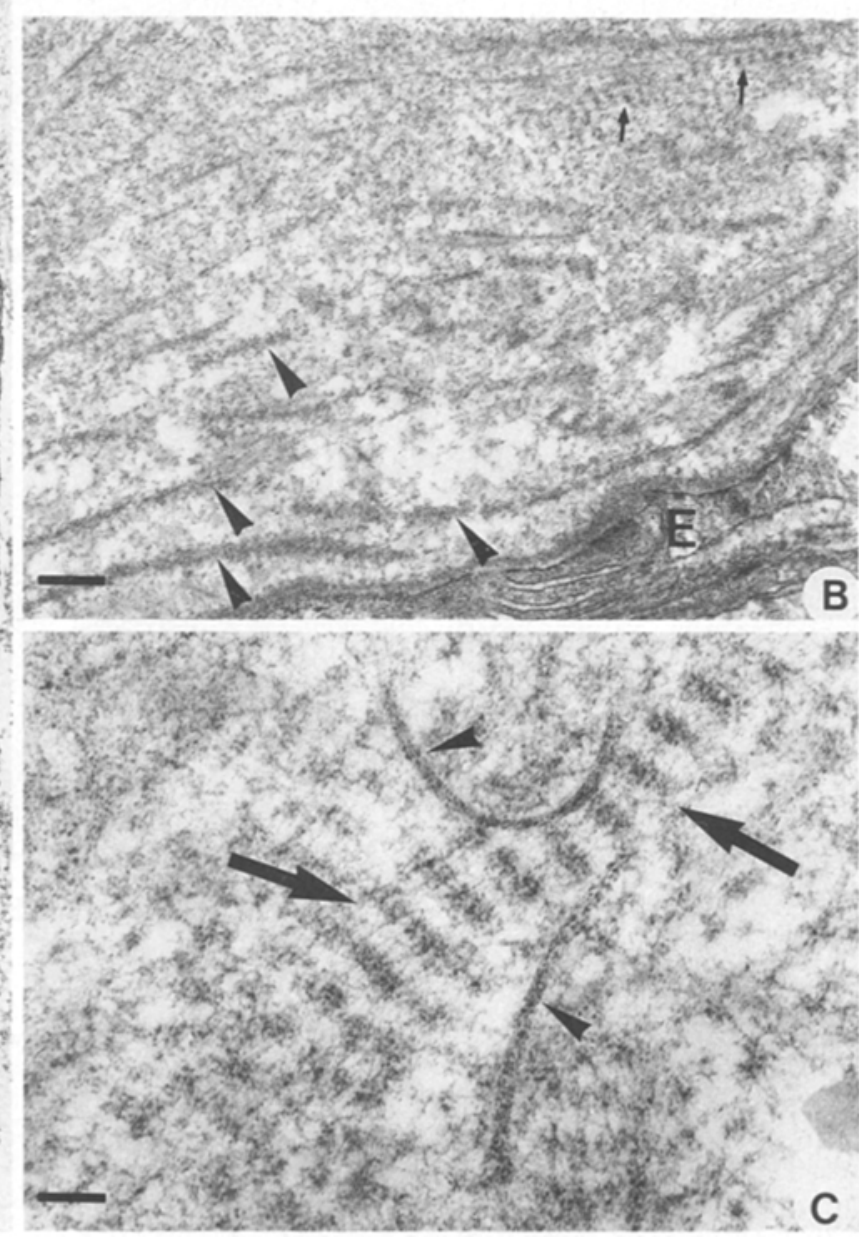

veil cells $(V)$. L, capillary lumen; $P$, pericyt; $E$, endothelial cell. (A $\times 12600$, bar $0.56 \mu \mathrm{m} ; \mathbf{B} \times 15600$, bar $0.45 \mu \mathrm{m})$. C Higher magnification of $\mathbf{A}(\times 60000$, bar $117 \mathrm{~nm})$. The broad-banded aggregates are made up of alternating light and dark bands, spaced with a periodicity of $100 \mathrm{~nm}$ (arrows). In addition, scattered collagen fibrils 20-25 nm thick (arrowheads) are seen 


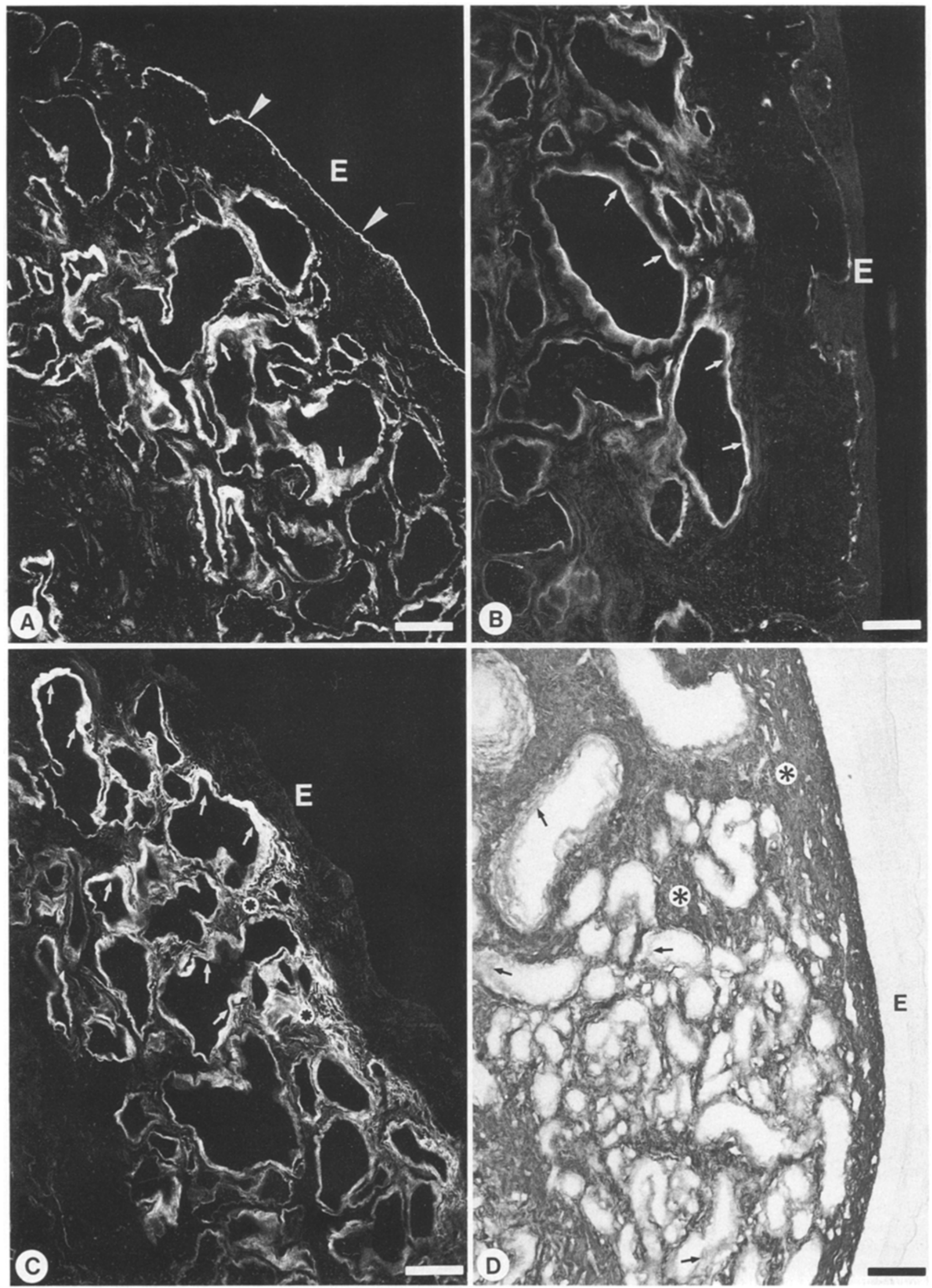


banded structures were in intimate association with the profiles of the basal lamina-like material. Native collagen fibrils with typical periodicity were only occasionally observed in these regions (Fig. 2C). In contrast to this, in the intercapillary stroma outside the sheath material large numbers of collagen fibrils were seen. Here, the ground substance stained electron-lucent and basal lamina-like material and broad-banded aggregates were not present. The pericapillary sheath material was often separated from the intercapillary stroma by fibroblasts showing characteristically long cytoplasmic processes (veil cells [46]). In many capillaries, the processes of the veil cells seemed to completely surround the sheath material (Fig. 2A).

\section{Immunohistochemistry}

Type IV collagen. The subpapillary region of normal skin showed a thin line of positive staining around nerves and capillaries and a broader line underneath the epidermis. Thus nerval, endothelial and epidermal basal lamina were stained selectively. In cherry haemangiomas, type IV collagen was stained in multilayered circular arrays around most of the capillaries (Fig. 3A). Around capillaries in which conventional histological stains indicated the presence of the typical sheath material, the whole sheath showed homogeneous positive staining for type IV collagen (Fig. 3A).

Laminin. In general, the staining for laminin corresponded to the staining for type IV collagen. Only in capillaries where thick sheath material was observed was staining for laminin not homogeneous being found only on the endothelial side of the sheath (Fig. 3B).

Type VI collagen. Pronounced positive staining for type VI collagen was seen around all cherry haemangioma capillaries (Fig. 3C). Type VI collagen stained most intensely and evenly distributed in the sheath material. However, in contrast to the staining for type IV collagen and laminin, positive staining was also seen throughout the entire intercapillary stroma of the cherry haemangiomas. In contrast to this, in normal skin from comparable regions much weaker staining for type VI collagen was seen. Only around vessels and nerves and immediately adjacent to the basal lamina of the epidermis was weak staining observed.

Fig. $3 \mathrm{~A}-\mathrm{D}$. Immunohistochemistry of a cherry haemangioma of a 40-year-old (A-C) and 57-year-old (D) donor. A Staining for type IV collagen. The sheath material of the capillaries stains intensely for type IV collagen (arrows). In addition the basal lamina of the epidermis $(E)$ is stained (arrowheads). B Staining for laminin is confined to the endothelial side of the sheath material (arrows). C Type VI collagen stains intensely and evenly distributed in the sheath material (arrows). Positive staining is also seen throughout the entire intercapillary stroma of the haemangioma (asterisks). D Staining for type III collagen. The collagenous fibres throughout the whole subpapillary layer stain positively for type III collagen (asterisks). The staining is much weaker in an area 4-10 $\mu \mathrm{m}$ thick around the individual cherry haemangioma capillaries (arrows). $E$, epidermis (paraffin sections, $\times 280$, bar $35.7 \mu \mathrm{m}$ )
Type III collagen. The collagenous fibres throughout the whole subpapillary layer stained positively for type III collagen. The staining was, however, much weaker in an area $4-10 \mu \mathrm{m}$ thick around the individual cherry haemangioma capillaries (Fig. 3D).

Hyaluronic acid. Hyaluronic acid was positively stained in the same regions where positive staining for type III collagen was also observed. An area $4-10 \mu \mathrm{m}$ thick around the cherry haemangioma capillaries remained unstained (Fig. 4).

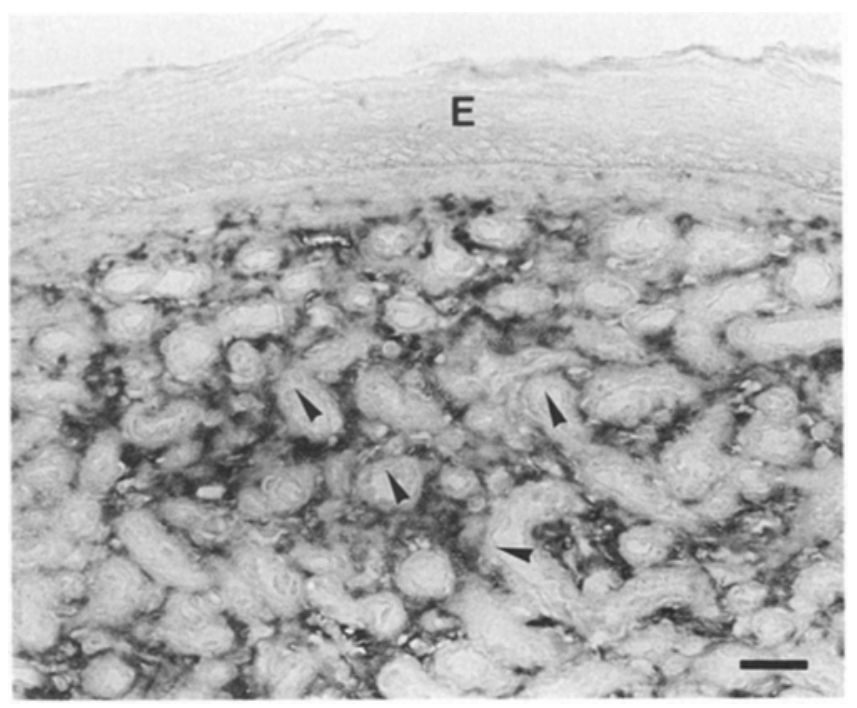

Fig. 4. Cherry haemangioma of a 31-year-old donor stained for hyaluronic acid (paraffin section, $\times 200$, bar $35 \mu \mathrm{m}$ ). The intercapillary stroma of the haemangioma is positively stained, while no staining is observed in an area $4-10 \mu \mathrm{m}$ thick around the capillaries (arrowheads)

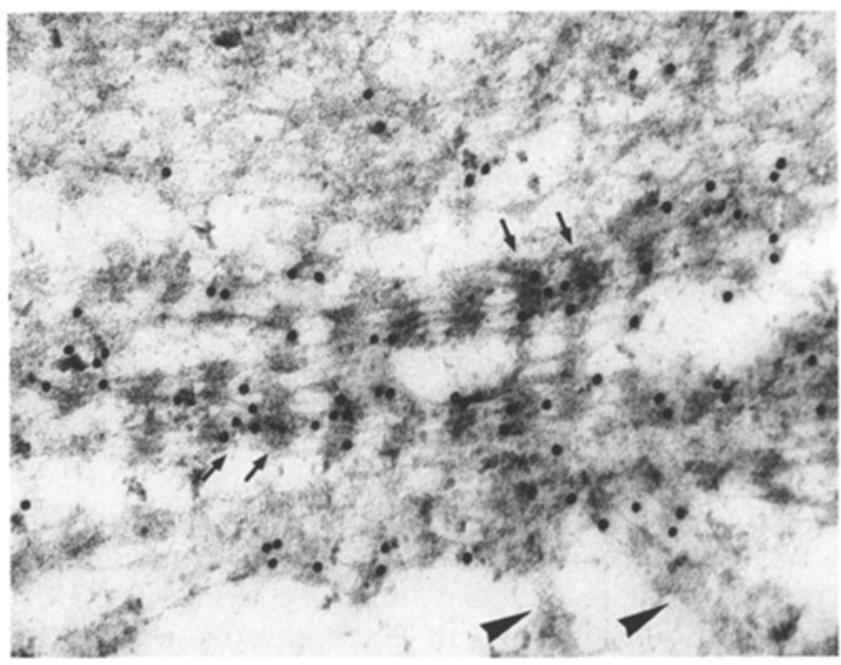

Fig. 5. Immunoelectron microscopy, using polyclonal antibodies to type VI collagen and gold-conjugated secondary antibodies (donor age, 62 years; $\times 98000$ ). Gold particles are localized to microfibrils and to the broad-banded aggregates (arrows). Collagen fibrils with periodicity of $67 \mathrm{~nm}$ are not labelled (arrowheads) 


\section{Ultraimmunohistochemistry}

Immunoelectron microscopy, using polyclonal antibodies against type VI collagen and gold-conjugated secondary antibodies, demonstrated that type VI collagen was strictly localized to microfibrils and to the broad-banded aggregates, but not to thin collagen fibrils with a periodicity of $67 \mathrm{~nm}$ (Fig. 5). Gold particles labelled both the longitudinal, filamentous transverse interbands and the dark bands of the broad-banded aggregates. No labelling was seen in control sections.

\section{Discussion}

The capillaries of cherry haemangiomas showed similar ultrastructural characteristics, such as dilated venous capillaries of postcapillary venules, to normal human skin $[2,43]$. A distinctive common feature of all these vessels was the presence of a multilaminated basal lamina $[2,43$, 46]. In addition, however, we found a pronounced thickening of the vascular wall around many of the cherry haemangioma vessels, corroborating the findings of Braverman and Keh-Yen [2]. U1trastructurally, these vessels were surrounded by a mainly homogeneous sheath of basement membrane-like material admixed with scattered collagen fibrils. Indeed, immunohistochemistry showed that type IV collagen and laminin, both essential macromolecules of basement membranes (for review see references [11,31], are major components of this sheath material.

Staining for type IV collagen was seen throughout the whole sheath material, whereas staining for laminin was more confined to the endothelial cell side. Comparable differences in localization of type IV collagen and laminin have been observed in normal basement membranes like those of the epidermis [10], of the glomerular capillary loops of murine [28] and rat [5] kidney, and of the vessels in the human iris [37]. The reason for the increased production of type IV collagen is not clear, but factors causing abnormal angiogenesis might also stimulate the production of excessive amounts of extracellular matrix. On the other hand, in vitro experiments have shown that basement membrane components, such as type IV collagen, promote differentiation and inhibit proliferation of vascular endothelial cells (for review see reference 27). Thus in situ basement membrane material might exhibit similar capabilities. An increased production of this material in benign vascular tumours, such as cherry haemangiomas, might be important for regulation and organization of vascular proliferation.

In accordance with previous studies [9, 44, 29], type III collagen and hyaluronic acid stained intensely in the normal subpapillary connective tissue surrounding the haemangiomas and in the connective tissue matrix between the capillary loops. In contrast to this, staining for type III collagen was very weak in the thickened vascular wall of the haemangioma capillaries; in these areas there were also ultrastructurally only a few scattered collagen fibrils with a periodicity of $67 \mathrm{~nm}$. Hyaluronic acid seemed not to be a major component of the thickened vascular wall in cherry haemangiomas, as no staining was found there.

Interestingly, we also observed a marked increase in type VI collagen which showed pronounced staining in the thickened vascular wall, but also throughout the perivascular connective tissue between the capillaries. In accordance with previous studies [4, 21], we observed that, in areas of normal skin surrounding the haemangiomas, there was only weak staining for type VI collagen in the subpapillary connective tissue near the epidermaldermal junction and in a thin area around nerves and capillaries. Normally, type VI collagen seems not to be an intrinsic basement membrane component [11]. Based on immunoelectron microscopic investigations it has been suggested that, in a similar manner to most extracellular matrices, type VI collagen in the skin forms a network of filaments $6-10 \mathrm{~nm}$ thick independent of collagen type I/III fibrils $[4,21]$. This network seems to anchor collagen type I/III fibres or the basement membranes of large interstitial structures, such as nerves and blood vessels, into surrounding connective tissue [21]. In accordance with our findings, an increase in type VI collagen has been observed in cerebral blood vessels in arterial hypertension [38], in experiments with haemodynamically stressed vessels [22], in the trabecular meshwork [25] and in the optic nerve [17] of eyes with increased ocular pressure. These findings might indicate that increased stress or strain on connective tissue matrices augments formation of type VI collagen.

Immunoelectron microscopic studies on the extracellular matrix of cultured fibroblasts and of rat tail tendons indicate that collagen type VI fibrils aggregate to form $100 \mathrm{~nm}$ 'beaded' filaments and fibrils $[3,4]$. Based on these findings it has been suggested that there is a close relationship between type VI collagen and broadbanded aggregates in situ with a similar periodicity of $100 \mathrm{~nm}$, which have also been referred to as long-spacing collagen, zebra collagen or Luse's bodies (for review see references 36 and 45]. Such aggregates have been described in many normal tissues including Descemet's membrane [18], the trabecular meshwork [12, 39], the synovial membrane [24, 35] and Meissner's corpuscles in the skin [15]. Recent immunoelectron microscopic studies on human trabeular meshwork [25] and synovial membrane in situ [35], and gel-cultured fibroblasts in vitro [40] confirm that there is indeed type VI collagen in these aggregates. These findings are supported by our study, as similar broad-banded aggregates in the sheath material of cherry haemangioma capillaries stain ultraimmunohistochemically for type VI collagen. There are no such aggregates in normal skin $[16,21]$ but in various skin lesions such as squamous cell carcinoma, malignant melanoma, primary or secondary amyloidosis, in inflammatory foci of a halonaevus and in lepromatous skin $[8,16]$. Interestingly, both in skin [20] and synovial membrane [35] formation of these aggregates has been induced by a short-period incubation with bacterial collagenase or other matrix metalloproteinases.

Type VI collagen is characteristically refractory to proteolytic enzymes; this might be related to its extensive intramolecular disulphide bonding [36, 45]. If type VI 
collagen fibrils form the broad-banded aggregates after collagenolytic removal of other fibrillar collagens, a similar process may acount for the formation of broadbanded aggregates around cherry haemangioma capillaries, as it is known that angiogenically stimulated capillary endothelial cells produce increased amounts of proteases and collagenases [14]. We hypothesize that type VI collagen serves as a scaffolding in tissues with high local concentrations of collagenolytic enzymes and that the increase in type VI collagen in cherry haemangiomas is related to this function.

Acknowledgements. We would like to thank A. Hauser, U. Maurer and B. Teschemacher for their excellent help in immunohistochemistry and G. Link for her expert assistance in electron microscopy. We would also like to thank M. Gößwein for his invaluable preparation of the photographs. This study was supported by grant Dre 124/6-2, Deutsche Forschungsgemeinschaft.

\section{References}

1. Becher J, Schuppan D, Hahn EG, Albert G, Reichart P (1986) The immunohistochemical distribution of collagens type IV, V, VI and of laminin in the human oral mucosa. Arch Oral Biol 31: $179-186$

2. Braverman IM, Keh-Yen A (1983) Ultrastructure and threedimensional reconstruction of several macular and papular telangiectases. J Invest Dermatol 81: 489-497

3. Bruns RR (1984) Beaded filaments and long-spacing fibrils: relation to type VI collagen. J Ultrastruct Res 89: 136-145

4. Bruns RR, Press W, Engvall E, Timpl R, Gross 3 (1986) Type VI collagen in extracellular, $100 \mathrm{~nm}$ periodic filaments and fibrils: identification by immunoelectron microscopy. J Cell Biol 103: 393-404

5. Courtoy PJ, Timpl R, Farquhar MG (1982) Comparative distribution of laminin, type VI collagen and fibronectin in the rat glomerulus. J Histochem Cytochem 30: 874-886

6. Crossmon G (1937) A modification of Mallory's connective tissue stain with a discussion of the principles involved. Anat Rec 69: 33-38

7 Duhamel RC, Johnson DA (1985) Use of nonfat dry milk to block nonspecific nuclear and membrane staining by avidin conjugates. J Histochem Cytochem 33: 711-714

8. Edwards RP (1975) Long-spacing collagen in skin biopsies from patients with lepromatous leprosy. Br J Dermatol 93: $175-182$

9. Fleischmajer R, Timpl R, Tuderman L, Raisher L, Wiestner M, Perlish JS, Graves PN (1981) UItrastructural identification of extension aminopropeptides of type I and III collagens in human skin. Proc Natl Acad Sci USA 78: 7360-7364

10. Foidart JM, Bere Jr EW, Yaar M, Rennard SI, Gullino M, Martin GR, Katz SI (1980) Distribution and immunoelectron microscope localization of laminin, a non-collagenous basement membrane glycoprotein. Lab Invest 42: 336-342

11. Furthmayr H (1988) Basement membranes. In: Clark RAF, Henson PM (eds) The molecular and cellular biology of wound repair. New York, pp 525-558

12. Garron LK, Feeney ML (1959) Electron microscopic studies of the human eye. II. Study of the trabeculae by light and electron microscopy. Arch Ophthalmol 62: 966-973

13. Graham RC, Kannovsky MJ (1966) The early stages of absorption of injected horseradish peroxidase in the proximal tubules of mouse kidney: Ultrastructural cytochemistry by a new technique. J Histochem Cytochem 14: 292-302

14. Gross JL, Moscatelli D, Rifkin DB (1983) Increased capillary endothelial cell protease in response to angiogenic stimuli in vitro. Proc Natl Acad Sci USA 80: 2623-2627

15. Hashimoto K (1973) Fine structure of the Meissner corpuscle of human palmar skin. $J$ Invest Dermatol 60: 20-28

16. Hashimoto K, Ohyama H (1974) Cross-banded filamentous aggregation in the human dermis. $J$ Invest Dermatol 62: $106-112$

17. Hernandez MR, Andrejewska WM, Neufeld AH (1990) Changes in the extracellular matrix of the human optic nerve head in primary open-angle glaucoma. Am J Ophthalmol 109: 180-188

18. Jakus MA (1956) Studies on the cornea. II. The fine structure of Descemet's membrane. J Biophys Biochem Cytol 2 [Suppl 4]: 243

19. Johnson GD, Davidson RS, McNamee KC, Russel G, Goodwin D, Holborow EJ (1982) Fading of immunofluorescence during microscopy: a study of the phenomenon and its remedy. $J$ Immunol Methods 55: 231-242

20. Kajikawa KI, Nakanishi T, Yamamura T (1980) The effect of collagenase on the formation of fibrous long spacing collagen aggregates. Lab Invest 43: 410-417

21. Keene DR, Engvall E, Glanville RW (1988) Ultrastructure of type VI collagen in human skin and cartilage suggests an anchoring function for this filamentous network. J Cell Biol 107, 1995-2006

22. Kittelberger R, Davis PF, Stehbens WE (1990) Type VI collagen in experimental atherosclerosis. Experientia 46: 264-267

23. Lever WF, Schaumburg-Lever G (1983) Tumors of vascular tissues. In: Histopathology of the skin, 6th edn. Lippincott, Philadelphia, pp 623-638

24. Linck G, Porte A (1981) B-cells of the synovial membrane. II. Relationship with the specific collagenous structure of the interstitium in the mouse. Cell Tissue Res 218: 117-121

25. Lütjen-Drecoll E, Rittig M, Rauterberg J, Jander R, Mollenhaver J (1989) Immunomicroscopical study of type VI collagen in the trabecular meshwork of normal and glaucomatous eyes. Exp Eye Res 48: 139-147

26. Lütjen-Drecoll E, Schenholm M, Tamm E, Tengblad A (1990) Visualization of hyaluronic acid in the anterior segment of rabbit and monkey eyes. Exp Eye Res 51: 55-63

27. Madri JA, Pratt BM (1988) Angiogenesis. In: Clark RAF, Henson PM (eds) The molecular and cellular biology of wound repair. Plenum, New York, pp 337-358

28. Madri JA, Roll J, Furthmayr H, Foidart JM (1980) Ultrastructural localization of fibronectin and laminin in the basement membrane of the murine kidney. J Cell Biol 86: 682-687

29. Mark K von der (1981) Localization of collagen types in tissues. Int Rev Connect Tiss Res 9: 265-324

30. Mark $H$ von der, Aumailley $M$, Wick $G$, Fleischmajer R, Timpl R (1984) Immunohistochemistry, genuine size and tissue localization of collagen VI. Eur J Biochem 142: 493-502

31. Martinez-Hernandez A, Amenta PS (1983) The basement membrane in pathology. Lab Invest 48:656-677

32. McLean IW, Nakane PK (1974) Periodate-lysine-paraformaldehyde fixative: a new fixative for immuno-electron microscopy. J Histochem Cytochem 22: 1077-1083

33. Murison AR, Sutherland JW, Williamson AM (1947) De Morgan's spots. Br Med J 1: 634-638

34. Odermatt BF, Lang AB, Rüttner JW, Winterhalter $\mathrm{KH}$, Trüeb B (1984) Monoclonal antibodies to human type IV collagen: useful reagents to demonstrate the heterotrimeric nature of the molecule. Proc Natl Acad Sci USA 81: 7343-7347

35. Okada Y, Naka K, Minamoto T, Ueda Y, Oda Y, Nakanishi I, Timpl R (1990) Localization of type VI collagen in the lining layer of normal and rheumatoid synovium. Lab Invest 63 : $647-656$

36. Rauterberg J, Jander R, Troyer D (1986) Type VI collagen : a structural glycoprotein with a collagenous domain. Front Matrix Biol 11: 90-109

37. Rittig M, Lütjen-Drecoll E, Rauterberg J, Jander R, Mollenhauer J (1990) Type VI collagen in the human iris and ciliary body. Cell Tissue Res 259: 305-312 
38. Roggendorf W, Ipitz H, Schuppan D (1988) Altered expression of collagen VI in brain vessels of patients with chronic hypertension. Acta Neuropathol 77: 55-60

39. Rohen JW (1962) Über das Ligamentum pectinatum der Primaten. Z Zellforsch 58: 403-421

40. Schlumberger W, Thie M, Rauterberg J, Kresse H, Robenek H (1989) Deposition and ultrastructural organization of collagen and proteoglycans in the extracellular matrix of gel-cultured fibroblasts. Eur J Cell Biol 50: 100-110

41. Schnyder UW, Keller R (1954) Zur Klinik und Histologie der Angiome. III. Zur Histologie und Pathogenese der senilen Angiome. Arch Dermatol Syph 198: 333-342

42. Schuppan D, Rühlmann T, Hahn EG (1985) Radioimmu- noassay for human type VI collagen and its application to tissue and body fluids. Ann Biochem 149: 238-247

43. Stehbens WE, Ludatscher RM (1968) Fine structure of senile angiomas of human skin. Angiology 19: 581-592

44. Tammi R, Ripellino JA, Margolis RU, Tammi M (1988) Localization of epidermal hyaluronic acid using the hyaluronate binding region of cartilage as specific probe. $\mathbf{J}$ Invest Dermatol 90: 412-414

45. Timpl R, Engel J (1987) Type VI collagen. In: Mayne R, Burgeson R, Mecham RP (eds) Structure and function of collagen types, Vol III. New York, pp 105-143

46. Yen A, Braverman IM (1976) Ultrastructure of the human dermal microcirculation: the horizontal plexus of the papillary dermis. J Invest Dermatol 66: 131-142 